\title{
AVALIAÇÃO DO EFEITO DO CONGELAMENTO NA RESISTÊNCIA À COMPRESSÃO E NA ABSORÇÃO D’ÁGUA DE CONCRETOS MOLDADOS COM AGREGADOS RECICLADOS
}

\author{
ALBAN, PEDRO \\ Engenheiro Civil \\ PUCRS \\ Rio Grande do Sul; Brasil \\ pedro.alban@acad.pucrs.br
}

\author{
ANDRADE, JAIRO \\ Professor \\ PUCRS \\ Rio Grande do Sul; Brasil \\ jairo.andrade@pucrs.br
}

\section{RESUMO}

Frente a escassez dos recursos naturais e a dificuldade na destinação de grandes volumes de resíduos na indústria da construção civil, apresenta-se necessária a busca por alternativas sustentáveis que solucionem ambos os problemas, sendo a incorporação de Resíduos de Construção e Demolição (RCD) em concretos uma destas práticas sustentáveis. Sua análise e caracterização demonstrou, entre outras características, maior porosidade e permeabilidade, propriedades as quais geralmente levam a redução de resistência do concreto. Contudo, estas características mostram-se positivas em situações de congelamento devido à capacidade de dissipação dos efeitos do aumento do volume da água passível de congelamento pelo seu alto índice de vazios. Neste contexto, este trabalho avaliou os efeitos do congelamento em concretos realizados com a incorporação de RCD. Para tanto, foram realizados ensaios em concretos com $25 \%, 50 \%$, $75 \%$ e $100 \%$ de substituição de agregados naturais pelos reciclados e submetidos a um ciclo de gelo e degelo com duração de 144h. Por fim, as amostras foram ensaiadas para verificação da absorção e da resistência à compressão. Os resultados mostraram que a incorporação de $25 \%$ e $50 \%$ de RCD ao concreto não altera de modo considerável sua absorção d'água, enquanto a incorporação de $25 \%, 50 \%$ e $75 \%$ de RCD ao concreto mostra pequena variação nos valores de resistência à compressão residual, após $48 \mathrm{~h}$ de congelamento.

Palavras-chave: Sustentabilidade, concreto, agregados reciclados, ciclos congelamento/degelo.

\begin{abstract}
Considering the scarcity of natural resources and the difficulty in disposing of large volumes of waste in the civil construction industry, it is necessary to search for sustainable alternatives that solve both problems, with the incorporation of Construction and Demolition Waste (CDW) into concrete one of these sustainable practices. Its analysis and characterization demonstrated, among other characteristics, greater porosity and permeability, properties that generally lead to a reduction in concrete strength. However, these characteristics are positive in freezing situations due to the dissipation capacity of the effects of increasing the volume of water subject to freezing by its high voids index. In this context, this work evaluated the effects of freezing in concrete performed with the incorporation of CDW. For this purpose, tests were performed on concrete with $25 \%, 50 \%, 75 \%$ and $100 \%$ replacement of natural aggregates by recycled ones and subjected to a $144 \mathrm{~h}$ ice and defrost cycle. Finally, the samples were tested for absorption and compressive strength. The results showed that the incorporation of $25 \%$ and $50 \%$ of CDW to the concrete does not change considerably its water absorption, while the incorporation of $25 \%, 50 \%$ and $75 \%$ of CDW to the concrete shows little variation in the values of residual compressive strength, after 48 hours of freezing.
\end{abstract}

Keywords: Sustainability, concrete, recycled aggregate, freezing.

\section{INTRODUÇÃO}

O grande volume de resíduos produzidos nas cidades brasileiras é um dos grandes problemas enfrentados pelo setor da construção civil (JÚNIOR et al., 2018). Thomas et al. (2018) explicam que diversos países afrontam a escassez de recursos naturais recorrendo a explorações inadequadas de pedreiras para suprir suas necessidades. Vibrações, poluição do ar e das fontes de água e deslizamentos de terra são alguns dos impactos de pedreiras não planejadas. Ações que envolvem a utilização de RCD capazes de substituir recursos naturais representam tecnologias de construção mais 
ecológicas sem tais impactos negativos, assim como a utilização de agregados reciclados incorporados ao concreto. Tam et al. (2005) citam a falta de equipamentos para triagem dos resíduos, experiência em operações de reciclagem de resíduos, supervisores e funcionários capacitados, conhecimento do mercado de materiais secundários e regulamentações ambientais e de segurança como fatores que colaboram para o baixo consumo de materiais reciclados na construção civil. Além disso os mesmos autores argumentam que somente o desenvolvimento e caracterização destes permitirá sua utilização como algo convencional.

Park et al. (2018) pontuam como o processo de reciclagem dos agregados pode interferir na qualidade do novo concreto, avaliando características e propriedades como absorção, formato, permeabilidade, composição e distribuição granulométrica. Xiao et al. (2018) realizaram pesquisas com a incorporação de RCD, avaliando as propriedades mecânicas de concretos realizados em parte com cimento reciclado. Thomas et al. (2018) efetuaram estudos na área de reciclagem de $\mathrm{RCD}$, chegando à conclusão que a substituição de $25 \%$ de agregado natural por agregado reciclado é recomendada em ambientes com agressividade moderada, onde o risco de deterioração da estrutura é insignificante ou pequeno. Já autores como Exteberria et al. (2007) explicam que os agregados reciclados são compostos basicamente de agregados originais e argamassa aderida, entre outros materiais em menores proporções (PARK et al., 2018).

Powers e Helmuth (1953) são precursores do estudo realizado por autores como Bogas et al. (2016) e Liu et al. (2018), que estudam situações onde o concreto é exposto ao congelamento, explicando como funcionam os mecanismos de geração da pressão hidráulica e difusão da água- gel no interior do concreto. Estes autores ilustram como a alta absorção dos agregados reciclados pode ser benéfica na situação de gelo e degelo, produzindo amostras com a incorporação de RCD. Ainda, há pesquisas similares com agentes incorporadores de ar cujos resultados também exibem capacidade de resistir ao congelamento (BOGAS et al., 2016).

Mehta e Monteiro (2006) discutem que concretos submetidos a temperaturas negativas sempre apresentam reduções nas resistências. Já autores como, mas Bogas et al. (2016) e Júnior et al. (2018) exibem o aumento da durabilidade de concretos realizados com a incorporação de RCD em situações de congelamento. Portanto, este estudo demonstra a boa performance dos concretos realizados com agregados reciclados submetidos ao resfriamento após cura de 28 dias imersos em água, mostrando que os mesmos são capazes de aliviar as pressões geradas pelos mecanismos da ação de congelamento.

Neste contexto, o presente trabalho visa avaliar a influência de temperaturas negativas no concreto realizado com a incorporação de agregados reciclados utilizando-se como parâmetros de estudo a resistência à compressão residual e a absorção. Para tanto, foi realizado um estudo sobre o comportamento do concreto submetido a temperaturas negativas bem como a avaliação de como a porosidade dos agregados de RCD pode contribuir positivamente para o aumento da durabilidade dos concretos expostos a situação de congelamento. Ademais, foram realizados ensaios reproduzindo concretos com teores de substituição de $0 \%, 25 \%, 50 \%, 75 \%$ e $100 \%$ de agregados reciclados submetidos a temperatura de $-17,7^{\circ} \mathrm{C}$ por $48 \mathrm{~h}$ após o período de cura de 28 dias. Por fim, foi verificada a resistência à compressão e absorção das amostras.

\section{PROCEDIMENTOS METODOLÓGICOS}

\subsection{Método de pesquisa}

O presente trabalho, do ponto de vista da sua natureza no que refere-se ao método de pesquisa, é uma pesquisa aplicada. De acordo com Silva e Menezes (2005), a pesquisa aplicada caracteriza-se por gerar conhecimentos para aplicação prática do problema, dirigidos à solução de temas específicos, envolvendo verdades e interesses locais. Pelo fato de trazer informações e conclusões mensuráveis, o presente estudo, sob perspectiva da abordagem do problema, é uma pesquisa quantitativa, pois de acordo com Silva e Menezes (2005), esta é capaz de traduzir em números opiniões e informações para posterior análise e classificação.

Em relação aos objetivos, a pesquisa é explicativa pois têm como preocupação central a identificação dos fatores que determinam ou que contribuem para a ocorrência dos fenômenos, como explicado por Gil (2008). Ainda segundo o autor, este tipo de pesquisa aprofunda o conhecimento da realidade pois explica racionalmente o porquê dos acontecimentos. Dentre os diferentes tipos de pesquisa, é o mais complexo e delicado, já que o risco de cometer erros aumenta consideravelmente.

Sob perspectiva dos procedimentos técnicos adotados, a pesquisa é de caráter experimental pois determina-se um objeto de estudo, selecionam-se as variáveis que seriam capazes de influenciá-lo e definem-se formas de controle e observação dos efeitos que a variável produz, possibilitando o desenvolvimento de conclusões (GIL, 2008). 


\subsection{Método de trabalho}

Para avaliação do efeito do congelamento no concreto realizado com agregados reciclados, foram moldados 50 corposde-prova para determinação da resistência à compressão e absorção dos concretos realizados com $0 \%, 25 \%, 50 \%, 75 \%$ e $100 \%$ de substituição de agregados de origem basáltica por RCD, em massa. Metade das amostras foram expostas a $48 \mathrm{~h}$ de congelamento após cura de 28 dias, permanecendo mais $96 \mathrm{~h}$ em descongelamento imersas em água, totalizando 144h. A outra metade das amostras permaneceu em água até $24 \mathrm{~h}$ antes dos testes, simbolizando a referência para o presente estudo. Por fim, foram realizados os ensaios de resistência à compressão e absorção no $35^{\circ}$ dia de idade das amostras.

\section{PROCEDIMENTO EXPERIMENTAL}

\subsection{Materiais}

Para realização das amostras, utilizou-se o cimento Portland de alta resistência inicial, com massa específica de 3,05 $\mathrm{kg} / \mathrm{dm}^{3}$ e massa unitária de $1,40 \mathrm{~kg} / \mathrm{dm}^{3}$. O agregado miúdo adotado foi a areia natural de origem quartzosa oriunda do Lago Guaíba, enquanto pedra britada de origem basáltica foi utilizada como agregado graúdo. A água de amassamento do concreto utilizada foi da rede pública de abastecimento. Os agregados reciclados utilizados no ensaio são resíduos de construção e demolição com resistência mecânica desconhecida obtidos da reforma de um edifício de concreto armado.

\subsubsection{Agregados}

Altos volumes de concreto chegam a todo momento em aterros, dificultando o controle das características dos resíduos de várias localizações diferentes. A determinação dos atributos e particularidades em cada processo de reciclagem de cada concreto de diferentes origens requer tempo e equipamentos de trituração em larga escala padronizados que possibilitem comparações entre si, além de uma infraestrutura capaz de realizar tais caracterizações. Por conseguinte, o prévio estudo do agregado reciclado traz mais certezas na dosagem do concreto e na previsão de suas futuras propriedades. Todavia, pela limitação de recursos, trabalhou-se com a incerteza das propriedades do RCD e adotou-se como desconhecida a resistência mecânica dos agregados de RCD. Contudo, foi possível determinar outras propriedades que caracterizam os agregados, graúdos e miúdos, envolvidos na pesquisa, expostas na Tabela 1.

Tabela 1: Características dos agregados utilizados

\begin{tabular}{llccc}
\hline CARACTERÍSTICA & NORMA TÉCNICA & AREIA & BRITA & RCD \\
\hline Massa unitária $\left(\mathrm{g} / \mathrm{cm}^{3}\right)$ & NBR NM 45 (ABNT, 2006) & 1,83 & 1,54 & 1,31 \\
Massa específica $\left(\mathrm{g} / \mathrm{cm}^{3}\right)$ & NBR NM 53 (ABNT, 2009) & 2,63 & 2,90 & 2,23 \\
Dimensão máxima característica (mm) & NBR NM 248 (ABNT, 2003) & 1,18 & 19 & 19 \\
Módulo de finura & NBR NM 248 (ABNT, 2003) & 2,40 & 6,82 & 6,98 \\
Absorção (\%) & NBR NM 53 (ABNT, 2009) & - & 0,52 & 11,94 \\
\hline
\end{tabular}

(fonte: Autor, 2018)

Para avaliação das quantidades de cada material presentes no agregado reciclado e sua posterior análise, separou-se manualmente os agregados de mesma origem de uma amostra de $5 \mathrm{~kg}$ de material. Sabe-se que os resíduos cerâmicos eram de paredes de alvenaria demolidas, com função de vedação. Os demais resíduos, como brita e argamassa, tem origem no concreto de pilares e vigas de um edifício de 3 andares. As exatas combinações de materiais e suas proporções em massa são visualizadas na Figura 1. 


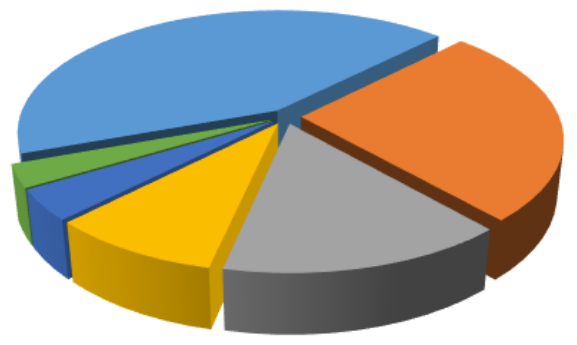

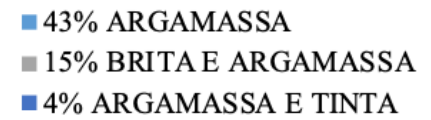

- 43\% ARGAMASSA

- 4\% ARGAMASSA E TINTA

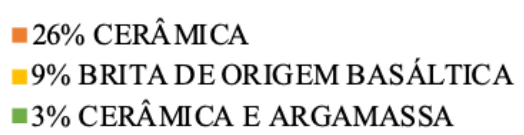

Figura 1: Percentuais da quantidade de materiais no agregado reciclado em massa

Seguiu-se o procedimento da NBR NM 248 (ABNT, 2003) para determinação das propriedades granulométricas. As curvas granulométricas dos agregados de RCD e dos agregados graúdos naturais (AGN) são exibidas na Figura 2.

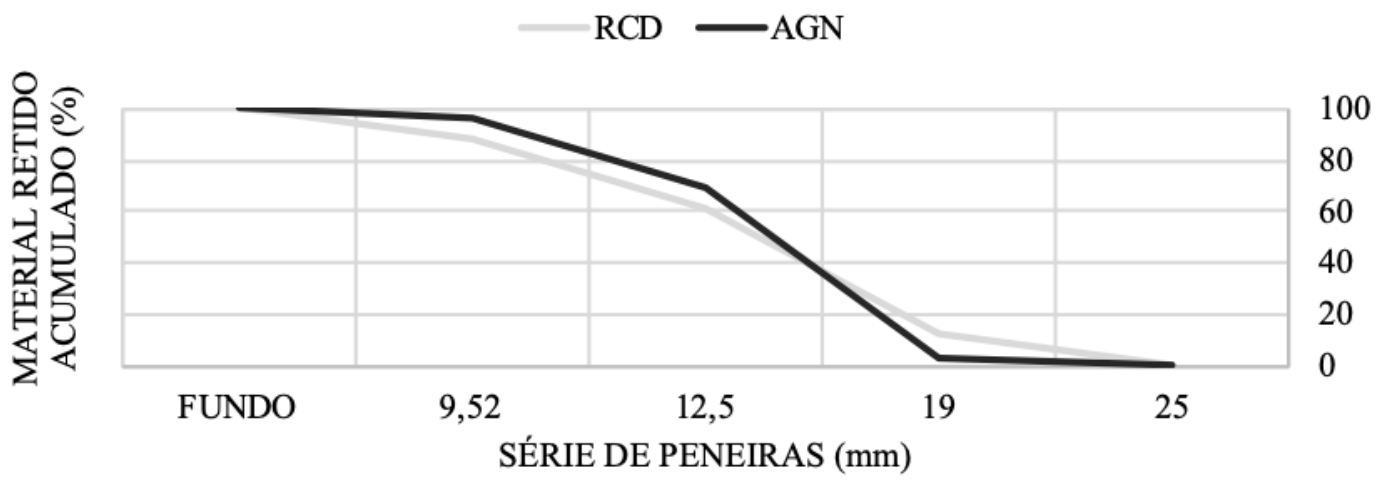

Figura 2: Curvas granulométricas dos agregados naturais e reciclados

\subsection{Dosagem dos concretos}

O traço utilizado teve relação a/c fixada em 0,4 sendo dosado pelo Método IPT/EPUSP, proposto por Helene e Terzian (1993). A escolha da relação a/c justifica-se a partir da compatibilização de pesquisas realizadas no laboratório e otimização dos recursos disponíveis. Na Tabela 2, estão apresentadas as proporções de materiais utilizados para moldagem das amostras para os 5 diferentes teores de substituição de agregados naturais pelos que incorporam RCD. O ensaio de abatimento do tronco de cone seguiu a padronização da NBR NM 67 (ABNT, 1998) e os respectivos resultados podem ser visualizados na Tabela 2 .

Tabela 2: Proporcionamento dos materiais empregados $\left(\mathrm{kg} / \mathrm{m}^{3}\right)$

\begin{tabular}{lccccc}
\hline Teor de RCD & $0 \%$ & $25 \%$ & $50 \%$ & $75 \%$ & $100 \%$ \\
\hline Cimento & 505,00 & 505,00 & 505,00 & 505,00 & 505,00 \\
Areia & 691,85 & 691,85 & 691,85 & 691,85 & 691,85 \\
Brita & 1060,50 & 795,38 & 530,25 & 265,13 & 0,00 \\
RCD & 0,00 & 203,87 & 407,74 & 611,62 & 815,49 \\
Água & 202,00 & 202,00 & 202,00 & 202,00 & 202,00 \\
\hline Abatimento $(\mathrm{mm})$ & 55 & 65 & 70 & 50 & 70 \\
\hline
\end{tabular}

Os procedimentos realizados para moldagem dos corpos-de-prova seguiram os padrões prescritos pela NBR 5738 (ABNT, 2015). Foram moldados 5 traços diferentes, variando somente os percentuais de brita de origem basáltica e 
RCD incorporados ao concreto. Logo, quantidades de cimento, água e areia permaneceram constantes ao longo do ensaio. Optou-se pela substituição de $75 \%$ e $100 \%$ de agregados, mesmo que apresentem resultados inferiores em desempenho nas bibliografias abordadas, para caracterização mais precisa da curva de desempenho em função da substituição de agregados. Anteriormente a introdução dos agregados reciclados no concreto, os mesmos permaneceram em saturação por $24 \mathrm{~h}$.

Destaque para o item pintura descascada nas paredes externas que apresentou a maior diferença entre ser observado e influenciar no conforto, cerca de $70 \%$, sendo então ignorado pela maioria das pessoas que veem este tipo de manifestação patológica. Para os demais itens esta porcentagem foi inferior a $50 \%$, ou seja, a maioria das pessoas que os observam sentem-se desconfortáveis. Em relação ao total de marcações das duas perguntas, a que questionava sobre as falhas mais comuns obteve 226 marcações e a que questionava sobre as que influenciavam no conforto obteve 177 marcações, cerca de $22 \%$ a menos.

\subsection{Procedimentos de cura e congelamento}

Após a etapa de moldagem das amostras, iniciou-se a desmoldagem dos exemplares após $24 \mathrm{~h}$. Logo depois, as 50 amostras foram levadas a um tanque de água, sendo que destas, 25 permaneceram imersas por 27 dias e as outras 25 por 33 dias. O grupo de amostras retirado após 27 dias de imersão foi levado a um freezer com temperatura interna de $17,7^{\circ} \mathrm{C}$. Estas amostras permaneceram em congelamento por $48 \mathrm{~h}$ e foram imersas em água a temperatura ambiente superior a $0^{\circ} \mathrm{C}$ novamente por mais $96 \mathrm{~h}$. As outras 25 amostras foram utilizadas para fins de comparação e não sofreram congelamento, apenas permaneceram imersas em água.

Após 34 dias de cura as 50 amostras foram retiradas da imersão. Aquelas utilizadas para determinação da absorção por imersão foram levadas a estufa, onde permaneceram por mais $24 \mathrm{~h}$, totalizando o ciclo de 35 dias. As amostras testadas para resistência à compressão foram apenas retiradas da imersão em seu $34^{\circ}$ dia, realizando-se o ensaio após $24 \mathrm{~h}$, totalizando o ciclo de 35 dias. Observa-se na Figura 3, a linha do tempo, em dias, adotada nos ensaios. As informações das amostras de controle estão dispostas à esquerda, enquanto as amostras que presenciaram o ciclo de gelo/degelo de 144 h estão exibidas à direita da Figura 3.

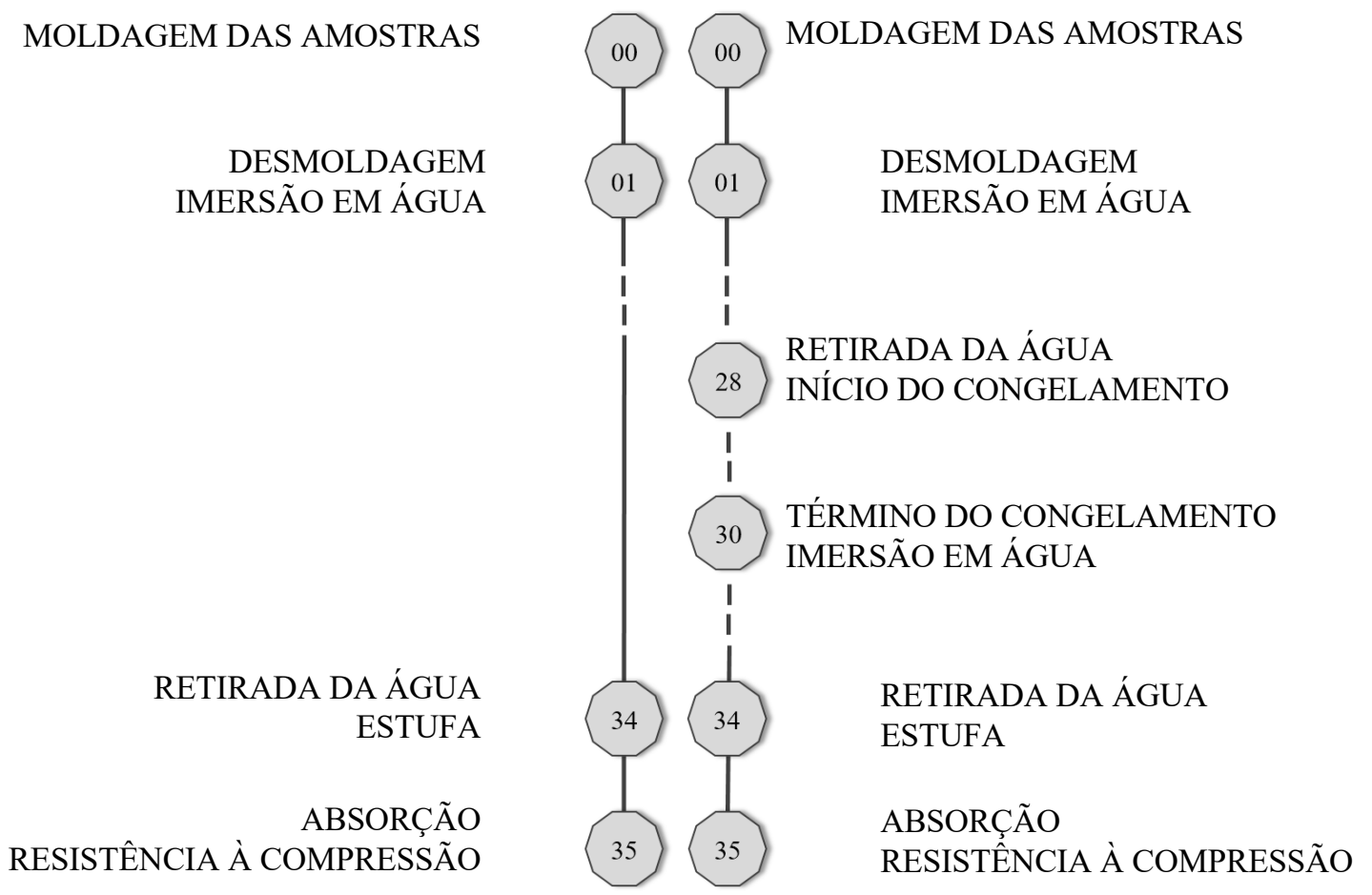

Figura 3: Linha do tempo da aplicação prática

Pela logística do laboratório e condições limitadas, não foi possível realizar todos os ensaios descritos na ASTM C666 (2015), adotados majoritariamente nas literaturas referentes a exposição de concretos a ciclos de gelo e degelo. O relatório fotográfico do desenvolvimento do ensaio é visualizado nos apêndices do presente trabalho. A definição de iniciar o congelamento ao período de 28 dias partiu da premissa que o concreto é desenvolvido para atingir sua 
resistência à compressão nesta idade, além de ser o tempo exato em que iniciam-se os ciclos de gelo e degelo nas literaturas citadas.

É importante destacar os procedimentos de ensaio adotados que são similares aqueles da ASTM C666 (2015). A temperatura de congelamento de $-17,7^{\circ} \mathrm{C}$ está dentro do limite de $-18^{\circ} \mathrm{C}\left( \pm 2^{\circ} \mathrm{C}\right)$. A fase de congelamento controlada com espaçamento entre os corpos-de-prova, de modo que possibilite a passagem de ar em todas as faces das amostras de maneira mais homogênea possível. O descongelamento foi realizado com imersão em água, promovendo o contato similar de água em todas as faces das amostras. Não tomou-se nota da temperatura da água na fase de descongelamento. A temperatura ideal seria de $4^{\circ} \mathrm{C}\left( \pm 2^{\circ} \mathrm{C}\right)$, conforme a ASTM C666 (2015).

A Tabela 3 ilustra resumidamente as principais diferenças entre os processos adotados para cura do concreto, procedimentos para ensaio de simulação de congelamento, números de ciclos de gelo e degelo, a duração de cada ciclo e a quais as temperaturas que estavam expostos os corpos-de-prova, nos trabalhos realizados por Bogas et al. (2016), Júnior et al. (2018) e Liu et al. (2018) e aqueles utilizados no presente artigo. A determinação do tempo de congelamento com $48 \mathrm{~h}$ deu-se pelas limitações de transporte e calendário para execução dos ciclos conforme a ASTM C666 (2015). Logo, adotou-se um único ciclo com a maior duração disponível em função do calendário, buscando o tempo de congelamento mais próximo dos estudos de referência.

Tabela 3: Comparativo de ensaios para avaliação de agregados reciclados submetidos ao congelamento

\begin{tabular}{|c|c|c|c|c|c|c|}
\hline BIBLIOGRAFIA & CURA & $\begin{array}{l}\text { ASTM C666 } \\
\quad(2015)\end{array}$ & CICLOS & $\begin{array}{l}\text { TEMPO } \\
\text { CICLO }\end{array}$ & \multicolumn{2}{|c|}{$\begin{array}{l}\text { VARIAÇÕES DE } \\
\text { TEMPERATURA }\end{array}$} \\
\hline $\begin{array}{l}\text { Bogas et al. } \\
(2016)\end{array}$ & $\begin{array}{l}\text { Desmoldagem após } 24 \mathrm{~h}, \\
\text { cura em água por mais } 27 \\
\text { dias, totalizando } 28 \text { dias }\end{array}$ & Procedimento A & 300 & $6 \mathrm{~h}$ & $-18^{\circ} \mathrm{C}$ & $4^{\circ} \mathrm{C}$ \\
\hline $\begin{array}{l}\text { Júnior et al. } \\
(2018)\end{array}$ & $\begin{array}{c}\text { Desmoldagem após } 24 \mathrm{~h}, \\
\text { cura em água por mais } 27 \\
\text { dias, totalizando } 28 \text { dias }\end{array}$ & Procedimento A & 300 & $5 \mathrm{~h}$ & $-17,8^{\circ} \mathrm{C}$ & $4,4^{\circ} \mathrm{C}$ \\
\hline Liu et al. (2018) & $\begin{array}{l}\text { Desmoldagem após } 24 \mathrm{~h} \text {, } \\
\text { cura por } 5 \text { meses em } \\
\text { ambiente externo e imersão } \\
\text { em água por } 14 \text { dias }\end{array}$ & Procedimento B & 40 e 80 & $24 \mathrm{~h}$ & $-35^{\circ} \mathrm{C}$ & $35^{\circ} \mathrm{C}$ \\
\hline Presente trabalho & $\begin{array}{l}\text { Desmoldagem após } 24 \mathrm{~h}, \\
\text { cura em água por mais } 27 \\
\text { dias, totalizando } 28 \text { dias }\end{array}$ & $\begin{array}{c}\text { Similar ao } \\
\text { Procedimento B }\end{array}$ & 1 & $48 \mathrm{~h}$ & $-17,7^{\circ} \mathrm{C}$ & $>0 \mathrm{C}$ \\
\hline
\end{tabular}

Ainda, destacam-se os itens estabelecidos no ensaio em função da disponibilidade que diferem da norma norte americana e demais bibliografias pesquisadas quanto à simulação de ciclos de gelo. O tempo do ciclo de gelo e degelo, não deve ser menor que $2 \mathrm{~h}$ e não maior que $5 \mathrm{~h}$, sendo no mínimo $20 \%$ do tempo de ciclo para descongelamento. No presente trabalho, foi realizado apenas 1 ciclo de gelo e degelo com duração de $144 \mathrm{~h}$, sendo $48 \mathrm{~h}$ para congelamento das amostras e 96h para o descongelamento das mesmas. Os exemplares seguiram padronização da NBR 5738 (ABNT, 2015) e foram realizados com diâmetro de $100 \mathrm{~mm}$ e altura de $200 \mathrm{~mm}$.

Conforme a ASTM C666 (2015), as amostras deveriam possuir largura, profundidade ou diâmetro de no mínimo $75 \mathrm{~mm}$ e máximo $125 \mathrm{~mm}$ e altura de no mínimo $275 \mathrm{~mm}$ e máximo $405 \mathrm{~mm}$. Outrossim, não seguiu-se o número de ciclos de gelo e degelo e tempo total do ensaio. Usualmente, adotam-se 300 ciclos de gelo/degelo com duração de $5 \mathrm{~h}$, totalizando $1500 \mathrm{~h}$ de ensaio. No presente artigo, adotou-se um único ciclo totalizando 144h. A escolha do período de 6 dias de ciclo, 2 dias de congelamento e 4 dias de descongelamento, iniciado aos 28 dias de cura do concreto, justifica-se também pela disponibilidade de operação nos laboratórios. Além do tempo de ciclo e da grande diferença entre o número de ciclos realizados, faz-se necessário destacar a diferença entre os Procedimentos A e B da ASTM C666 (2015). A principal delas está na fase de congelamento do ciclo: enquanto o Procedimento A é realizado com imersão total das amostras em água, o Procedimento B é realizado com circulação de ar entre os corpos-de-prova. Não foi possível realizar o Procedimento A devido à capacidade do freezer. 


\section{RESULTADOS E DISCUSSÃO}

\subsection{Absorção por imersão}

Os resultados de absorção, antes e depois do congelamento, estão apresentados na Figura 4. Diante destes, é possível constatar o aumento da absorção à medida que aumenta o percentual de substituição de agregados, antes e depois do congelamento. Ainda, após a ação do resfriamento, destacam-se dois grupos distintos de resultados no ensaio de absorção após o ciclo de 144h de gelo de gelo.

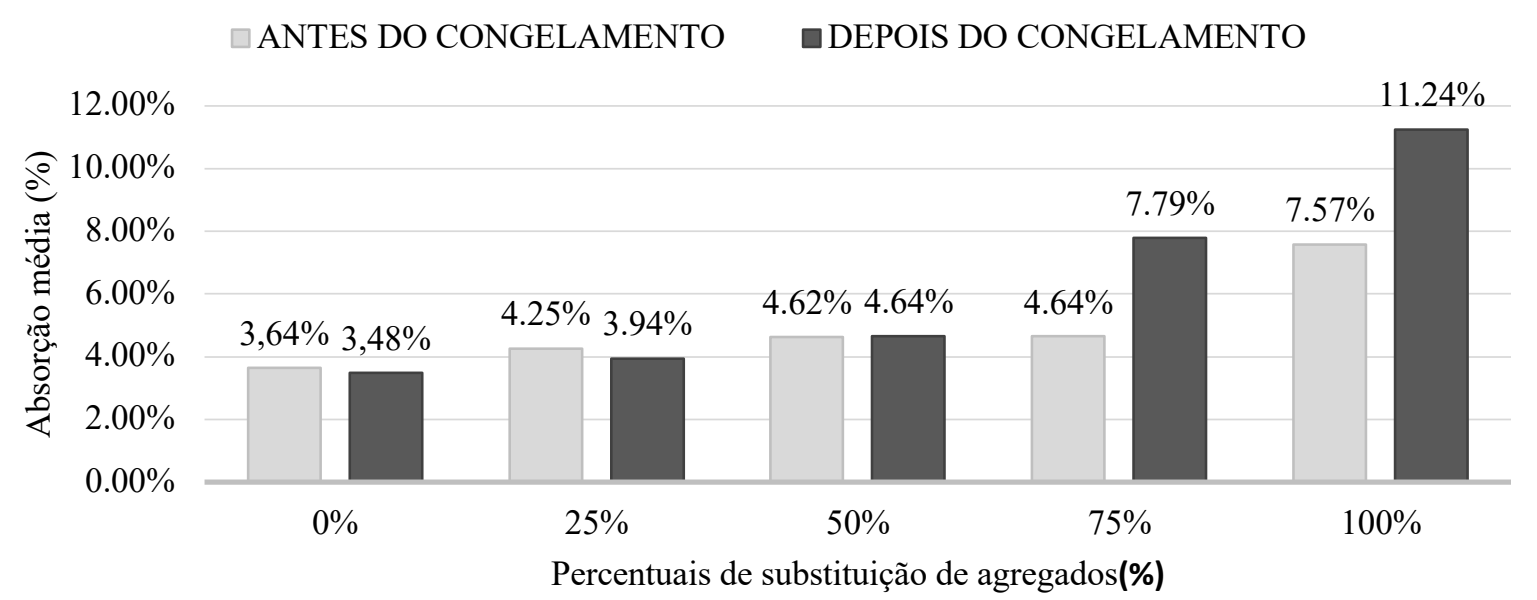

Figura 4: Resultados de absorção para $0 \%, 25 \%, 50 \%, 75 \%$ e $100 \%$ de substituição de agregados

As amostras com $0 \%, 25 \%$ e 50\% de incorporação de RCD não apresentam variação relevante na absorção, indicando que a estrutura interna das amostras manteve-se íntegra e que não há deterioração pelos mecanismos da ação do congelamento para os teores citados com somente $48 \mathrm{~h}$ de exposição ao congelamento. Já para as amostras com $75 \% \mathrm{e}$ $100 \%$ de agregados sustentáveis, observa-se que o congelamento de $48 \mathrm{~h}$ foi capaz de interagir com a microestrutura do concreto, provocando o aumento acentuado da absorção. Assim como observado por Júnior et al. (2018), este aumento da absorção por imersão é relacionado ao aumento do diâmetro dos capilares após o congelamento da água e crescimento dos cristais de gelo, visualizado nas amostras com os $75 \%$ e $100 \%$ de substituição de agregados, indicando que estes percentuais levam a concretos menos duráveis em relação aos teores de menor incorporação de RCD.

\subsection{Resistência à compressão}

Realizou-se o ensaio conforme a NBR 5739 (ABNT, 2018) para definição das resistências a compressão. Optou-se pelo procedimento da medição da resistência à compressão das amostras após o congelamento pela impossibilidade de realizar os principais testes citados na ASTM C666 (2015), que ilustram os limites para considerar o concreto resistente aos ciclos de gelo e degelo. Entretanto, como demonstrado na NBR 6118 (ABNT, 2014), a resistência à compressão do concreto é diretamente proporcional ao seu módulo dinâmico de elasticidade, que por sua vez é proporcional ao fator de durabilidade, e sua determinação auxilia na avaliação da resistência e durabilidade do concreto exposto ao congelamento, cujos respectivos resultados podem ser visualizados na Figura 5. 


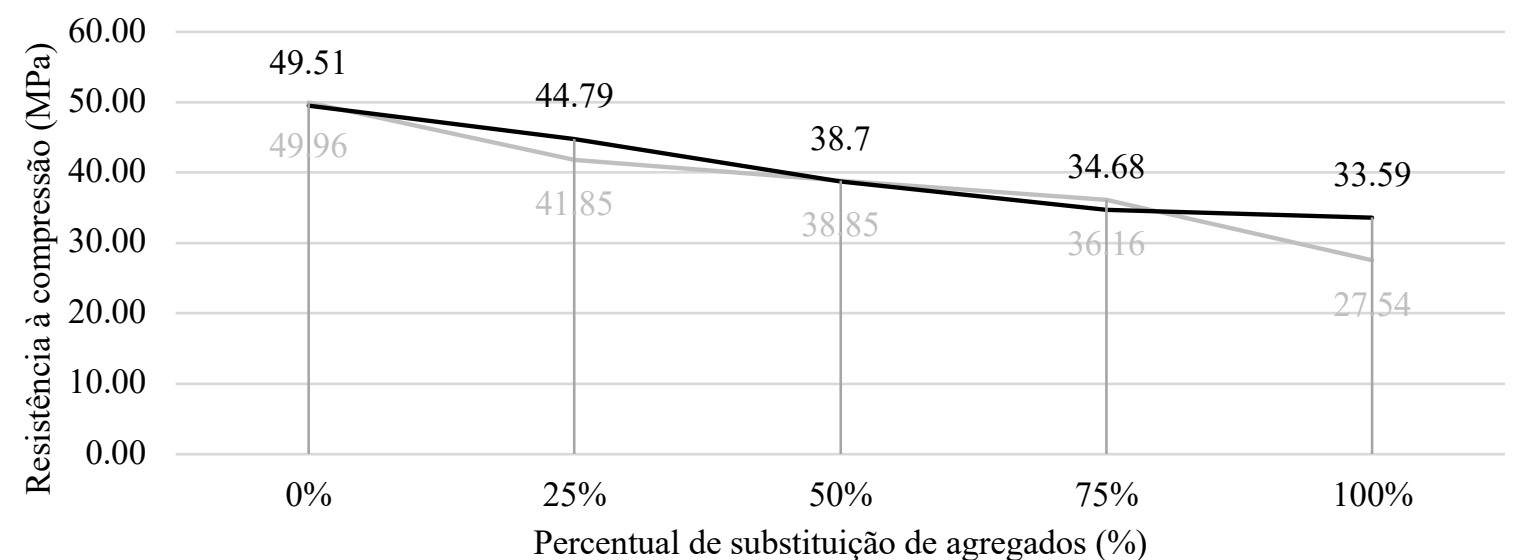

Percentual de substituição de agregados (\%)

\section{- DEPOIS DO CONGELAMENTO — — ANTES DO CONGELAMENTO}

Figura 5: Resistência à compressão dos concretos em função do teor de substituição de agregados (MPa)

Como observado nas análises desenvolvidas por Thomas et al. (2018), ocorre a diminuição da resistência à compressão do concreto ao passo que aumenta o teor de substituição de agregados naturais pelos RCD. Verifica-se o mesmo comportamento do concreto após o ciclo de $144 \mathrm{~h}$ realizado na presente aplicação experimental. Ademais, constata-se repercussão semelhante na pesquisa realizada por Bogas et al. (2016), na qual a substituição de $20 \%$ a $50 \%$ de agregados naturais pelos RCD apresenta mínimas variações na resistência à compressão de concretos expostos ao congelamento.

Observa-se que o tempo de congelamento é um fator importante na durabilidade de concretos congelados. Enquanto o concreto que apresentou melhor desempenho após 300 ciclos de congelamento teve $70 \%$ de resistência à compressão residual na análise de Bogas et al. (2016), os presentes resultados apresentaram valores residuais muitos similares, por vezes até superiores. Com a realização completa dos ciclos de gelo/degelo, esperam-se resultados próximos dos percentuais residuais obtidos pelos referidos autores. Embora constate-se maior resistência à compressão em 3 dos 5 traços realizados submetidos ao congelamento, atenta-se para a tendência estatística dos resultados do experimento prático. As resistências residuais a compressão dos traços realizados com teores de $25 \%$ e $75 \%$ de substituição de agregados convergem para o comportamento proposto por Bogas et al. (2016) e Júnior et al. (2018) quando avaliada a linha de tendência exponencial dos resultados obtidos, exposta na Figura 12, no qual admite-se um teor ótimo de substituição de agregados de 15-20\%. Os demais resultados de resistência à compressão residual são vistos na Figura 6.

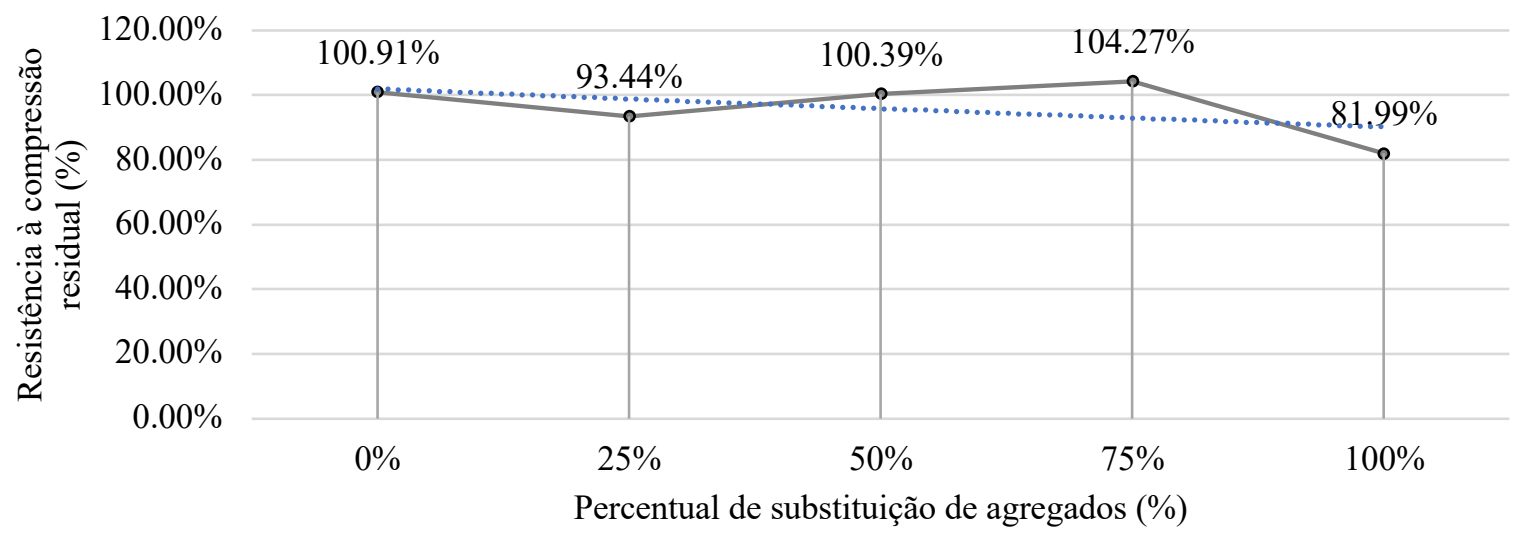

Figura 6: Resistência à compressão residual após 1 ciclo de congelamento

Observa-se que o congelamento contínuo de apenas $48 \mathrm{~h}$ não altera os valores de resistência à compressão para concretos com percentuais de substituição de $0 \%, 25 \%, 50 \%$ e $75 \%$ de agregados. Para os percentuais citados, todos os resultados de resistência à compressão residual obtidos são superiores a $93 \%$. Visualizam-se resultados similares no estudo de Bogas et al. (2016), no qual mesmo as amostras com relação a/c $=0,5$ apresentaram módulo dinâmico de elasticidade residual em conformidade com os limites da ASTM C666 (2015) após 50 ciclos de gelo/degelo. Outrossim, a repercussão da experimentação prática foi equivalente ao estudo de Júnior et al. (2018), no qual concretos com teores 
de incorporação de $\mathrm{RCD}$ de $0 \%, 15 \%, 25 \%$ e $50 \%$ só começam a apresentar queda na resistência à compressão após completos 150 ciclos de congelamento.

No entanto, as amostras com $100 \%$ de substituição de agregados apresentaram redução de aproximadamente $18 \%$ na resistência à compressão, ratificando a queda de desempenho de concretos com substituição completa de agregados naturais em situações de congelamento exposta por Liu et al. (2018). Portanto, constata-se que breves ciclos de congelamento, após cura de 28 dias, não alteram o desempenho do concreto quanto a durabilidade e resistência mecânica para as amostras que tiveram, em parte, agregados basálticos.

\section{CONSIDERAÇÕES FINAIS}

Avalia-se como positiva a incorporação de RCD para realização de concretos que venham a sofrer breves processos de congelamento durante sua vida útil. Os corpos-de-prova com substituição de agregados de $25 \%$ e $50 \%$ não exibem alteração relevante na absorção, enquanto os exemplares com incorporação de $25 \%, 50 \%$ e $75 \%$ de RCD apresentam pequena variação nos valores de resistência à compressão residual, após 48h contínuas de congelamento.

Ainda, faz-se necessário destacar aspectos que, de certo modo, possam ter influenciado na variabilidade dos resultados obtidos. O desconhecimento da resistência mecânica dos agregados de RCD, o número pequeno de amostras realizadas, a alta variabilidade dos componentes dos agregados reciclados, a não padronização dos procedimentos para simulação do congelamento conforme determina a ASTM C666 (2015), o não controle da temperatura durante as etapas do ensaio, além das limitações infraestruturas.

O bom desempenho geral das estruturas que incorporam resíduos sólidos da construção civil já é realidade, e seu estudo recente aponta esta como uma tecnologia com muito potencial de crescimento. A mudança do processo pragmático de destinação dos rejeitos dos canteiros de obra, possibilitando absorver parte destes resíduos no próprio ciclo da construção, deve ser mais explorada. Ao mesmo tempo que preserva o ecossistema e os recursos naturais, evita que materiais com alto desempenho sejam descartados em aterros.

Embora ainda pouco aplicável a nível nacional, a avaliação do comportamento de concretos produzidos com a incorporação de RCD, expostos ou não a ciclos de congelamento, ultrapassa fronteiras. A pesquisa com envolvimento de resíduos reciclados expõe diversos benefícios, caracteriza suas desvantagens, determina situações de aplicabilidade e promove a utilização de materiais com fontes sustentáveis. Em larga escala, como realizado com sucesso em diversos países desenvolvidos, o processo de reciclagem em canteiros de obras ou de demolições, ou com origem destes, soluciona um problema público de destinação de grandes volumes de resíduos sólidos.

\section{REFERÊNCIAS}

AMERICAN SOCIETY FOR TESTING AND MATERIALS. ASTM C666: Standard Test Method for Resistance of Concrete to Rapid Freezing and Thawing. 15 ed. West Conshohocken, 2015.

ASSOCIAÇÃO BRASILEIRA DE NORMAS TÉCNICAS. NBR 14931: Execução de estruturas de concreto Procedimento. 2 ed. Rio de Janeiro, 2004.

ASSOCIAÇÃO BRASILEIRA DE NORMAS TÉCNICAS. NBR 12655: Concreto de cimento Portland - Preparo, controle, recebimento e aceitação - Procedimento. Rio de Janeiro, 2015.

ASSOCIAÇÃO BRASILEIRA DE NORMAS TÉCNICAS. NBR 248: Agregados - Determinação da composição granulométrica. Rio de Janeiro, 2004.

ASSOCIAÇÃO BRASILEIRA DE NORMAS TÉCNICAS. NBR 5738: Concreto - Procedimento para moldagem e cura de corpos de prova. Rio de Janeiro, 2016.

ASSOCIAÇÃO BRASILEIRA DE NORMAS TÉCNICAS. NBR 5739: Concreto - Ensaio de compressão de corpos de prova cilíndricos. Rio de Janeiro, 2018.

ASSOCIAÇÃO BRASILEIRA DE NORMAS TÉCNICAS. NBR 9778: Argamassa e concreto endurecidos Determinação da absorção de água, índice de vazios e massa específica. Rio de Janeiro, 2005.

ASSOCIAÇÃO BRASILEIRA DE NORMAS TÉCNICAS. NBR NM 45: Agregados - Determinação da massa unitária e do volume de vazios. Rio de Janeiro, 2006.

ASSOCIAÇÃO BRASILEIRA DE NORMAS TÉCNICAS. NBR NM 53: Agregado graúdo - Determinação da massa específica, massa específica aparente e absorção de água. Rio de Janeiro, 2009. 
ASSOCIAÇÃO BRASILEIRA DE NORMAS TÉCNICAS. NBR NM 67: Concreto - Determinação da consistência pelo abatimento do tronco de cone. Rio de Janeiro, 1998.

ASSOCIAÇÃO BRASILEIRA DE NORMAS TÉCNICAS. NBR NM 6118: Projetos de estruturas de concreto Procedimento. Rio de Janeiro, 2014.

BOGAS, J. ; BRITO, J.; RAMOS, D. Freeze-thaw resistance of concrete produced with fine recycled concrete aggregates. Journal Of Cleaner Production, p.294-306, 2016.

EXTEBERRIA, M. et al. Influence of amount of recycled coarse aggregates and production process on properties of recycled aggregate concrete. Cement and Concrete Research, v. 37, p.735-742, 2007.

GIL, A. C. Métodos e técnicas de pesquisa social. 6.ed. São Paulo: Atlas, 2008.

HELENE, Paulo; TERZIAN, Paulo. Manual de Dosagem e Controle do Concreto. São Paulo: Pini, 1993.

JÚNIOR, N. S. A.; SILVA, G.A.O.; RIBEIRO, D.V.. Effects of the incorporation of recycled aggregate in the durability of the concrete submitted to freeze-thaw cycles. Construction And Building Materials, v. 161, p.723730, 2018.

LIU, K.; YAN, J.; ZOU, C. A pilot experimental study on seismic behavior of recycled aggregate concrete columns after freeze-thaw cycles. Construction And Building Materials, Harbin, v. 164, p.497-507, 2018.

MEHTA, P. K.; MONTEIRO, P. J. M. Concreto: estrutura, propriedades e materiais. 5. ed. São Paulo: Pini, 2006.

PARK, S. et al. Crushing characteristics of a recycled aggregate from waste concrete. Construction And Building Materials, República da Coréia, v. 160, p.100-105, 2018.

POWERS, T.C.; HELMUTH, R.A.. Theory of volume changes in hardened portland-cement paste during freezing. In: Highway Research Board Proceedings. (Comp.). Proceedings of the Thirty-Second Annual Meeting of the Highway Research Board. 32. ed. Washington: Highway Research Board, 1953. p. 285-297.

SILVA, E. L.; MENEZES, E. M. Metodologia da pesquisa e elaboração de dissertação. $4^{\mathrm{a}}$ ed. Rev. Atual, Florianópolis, Laboratório de Ensino a Distância da UFSC, 2005.

TAM, V. W.Y.; GAO, X.F.; TAM, C.M.. Microsctructural analysis of recycled aggregate concrete produced from two-stage mixing approach. Cement And Concrete Research, , v. 35, p.1195-1203, 2015.

THOMAS, J.; THAICKAVIL, N.; WILSON, P.M.. Strength and durability of concrete containing recycled concrete aggregates. Journal Of Building Engineering, Índia, p.349-365, 2018.

XIAO, J. et al. Mechanical proprieties of concrete mixed with recycled powder produced from construction and demolition waste. Journal Of Cleaner Production, Shangai, v. 188, p.720-731, 2018. 